\title{
The homeo domain protein rough is expressed in a subset of cells in the developing Drosophila eye where it can specify photoreceptor cell subtype
}

\author{
Bruce E. Kimmel, Ulrike Heberlein, and Gerald M. Rubin \\ Howard Hughes Medical Institute and Department of Molecular and Cell Biology, University of California at Berkeley, \\ Berkeley, California 94720 USA
}

The Drosophila homeo box gene rough is required in photoreceptor cells $\mathbf{R} 2$ and $\mathbf{R} 5$ for normal eye development. We show here that rough protein expression is limited to a subset of cells in the developing retina where it is transiently expressed for $30-60 \mathrm{hr}$. The rough protein is first expressed broadly in the morphogenetic furrow but is rapidly restricted to the R2, R3, R4, and R5 precursor cells. Ubiquitous expression of rough under the control of the hsp 70 promoter in third-instar larvae supresses the initial steps of ommatidial assembly. Structures derived from other imaginal discs are not affected. Ectopic expression of rough in the R7 precursor, through the use of the sevenless promoter, causes this cell to develop into an R1-6 photoreceptor subtype; however, this cell still requires sevenless function for its neural differentiation. Taken together with previous analyses of the rough mutant phenotype, these results suggest that the normal role of rough is to establish the unique cell identity of photoreceptors R2 and R5.

[Key Words: Homeo domain; eye development; Drosophila melanogaster; rough; ectopic expression; sevenless]

Received January 9, 1990; revised version accepted February 21, 1990.

The Drosophila eye is composed of $\sim 800$ unit eyes called ommatidia. Each ommatidium contains a stereotyped arrangement of 20 cells in which each cell can be identified by its morphology and position (Dietrich 1909; Ready et al. 1976). Eight of these cells are photoreceptors: six outer cells, R1-R6, and two smaller central cells, R7 and R8. The adult retina develops from an undifferentiated epithelial monolayer, the eye imaginal disc, beginning in the third instar larva (Ready et al. 1976; Tomlinson and Ready 1987al. Organization of cells into ommatidia begins in an indentation in the disc, called the morphogenetic furrow, which moves from posterior to anterior across the eye disc over a 2-day period. Thus, ommatidial assembly occurs asynchronously across the anterior-posterior axis of the eye disc such that each column of developing ommatidia is $\sim 2 \mathrm{hr}$ more developmentally advanced than the adjacent column to the anterior. In the morphogenetic furrow, five cells form a circular precluster that eventually gives rise to five of the eight photoreceptor cells of an ommatidium. Neuronal differentiation of these five photoreceptor precursors occurs in a stereotyped order: R8, R2, and R5, and R3 and R4 (Tomlinson and Ready 1987a). Undifferentiated cells surrounding the precluster are recruited sequentially to complete assembly of the ommatidium.

Ommatidial assembly occurs independently of cell lineage and must therefore depend on positional information to supply developmental cues (Ready et al. 1976; Lawrence and Green 1979|. Position interpretation and signaling are thought to be mediated by the precise cellular contacts formed in the developing ommatidium, the fate of a newly recruited cell being specified by the unique contacts it forms as it joins the developing ommatidium. Mutations like sevenless (for review, see Tomlinson 1988), rough (Tomlinson et al. 1988), and boss (Reinke and Zipursky 1988), which appear to disrupt the signal transmission process during ommatidial assembly, provide evidence in support of this view. The rough gene encodes a protein containing the DNAbinding homeo domain (Saint et al. 1988; Tomlinson et al. 1988|. Mosaic analysis shows that the rough gene is required in photoreceptors $\mathrm{R} 2$ and $\mathrm{R} 5$ for normal ommatidial assembly to occur. These cells are added to developing ommatidia normally, however, and the next cells to be added, R3 and R4, fail to differentiate appropriately (Tomlinson et al. 1988).

The results of Tomlinson et al. (1988) suggest that the rough protein is a transcription factor that regulates the generation of a signal in R2 and R5 that is required to induce $\mathrm{R} 3$ and $\mathrm{R} 4$ to differentiate normally. The rough mutation does not affect the early differentiation of R2 and R5, indicating that rough function is not required for these cells to adopt a photoreceptor cell fate. These ex- 


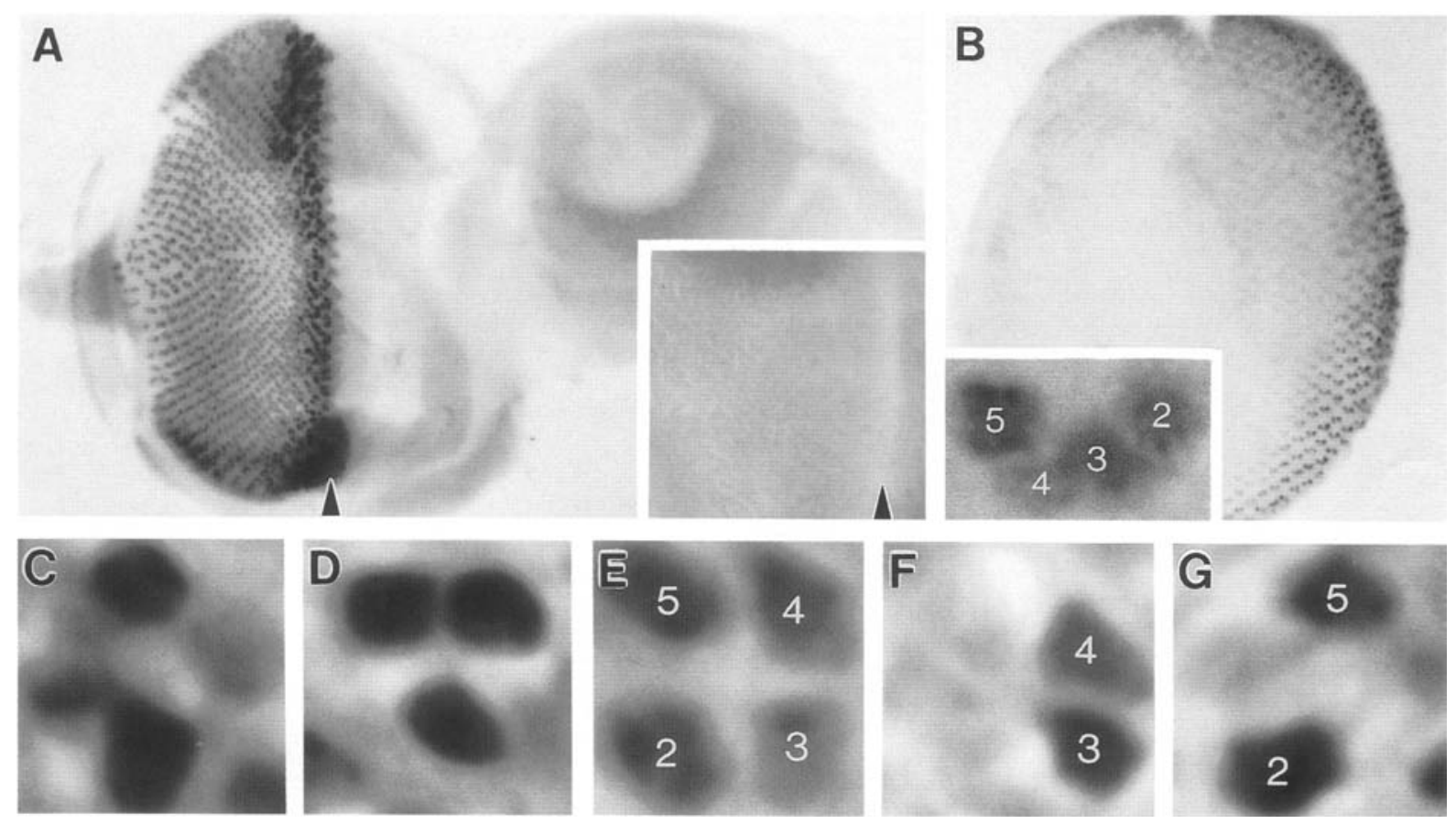

Figure 1. Expression of rough protein during wild-type Drosophila eye development. A third-instar larval eye-antennal disc $(A)$ and a 40 -hr pupal retina $(B)$ stained with the anti-rough MAbrol are shown. Anterior is to right. (A, inset) An eye disc from a larva homozygous for the null rough allele ${ }^{x 63}$ stained with MAbrol. ro ${ }^{x 63}$ is a small X-ray-induced deletion near the $5^{\prime}$ end of the rough-coding region that results in a frameshift after the thirty-first codon (U. Heberlein, unpubl.). The lack of detectable rough protein in this disc demonstrates the specificity of MAbrol. The arrowhead in $A$ marks the position of the morphogenetic furrow where rough protein was first detected. rough protein was localized in the cell nucleus. Magnifications in $A, A$ inset, and $B$ are $250 \times, 350 \times$, and $200 \times$, respectively. Phase-contrast images of single ommatidial clusters during different developmental stages of the larval eye disc $\langle C-G$, $6500 \times)$ and the pupal retina $(B$, inset, $5200 \times)$ are also shown. In the morphogenetic furrow, more than four nuclei per cluster stained with MAbrol, as can be seen by examining apical $(C)$ and basal $\langle D|$ focal planes. Because three-dimensional reconstructions have not been performed for this developmental stage, we are unable to establish conclusively the identities of the cells in the furrow that stain with MAbrol. However, just posterior of the furrow in immature eight-cell clusters, only four nuclei in the apical focal plane $(E)$ and none in the basal plane (data not shown) stained with MAbrol. In ommatidia that have developed to the symmetrical eight-cell cluster and two cone cell stages (Tomlinson 1985), four nuclei still stained with MAbrol; however, at this stage of development, two of the nuclei were located apically $(F)$ and two were more basal in the disc $(G)$. The same four nuclei were also seen staining in the 40 -hr pupal retina ( $B$, inset). The characteristic movements of these nuclei (Tomlinson 1985) identify these photoreceptor precursor cells as R2, R3, R4, and R5. For example, the four nuclei were observed first in the same focal plane, after which the nuclei of R2 and R5 sank basally. Furthermore, the R4 cell moved out of the cluster later in ommatidial development. Because the morphogenetic furrow reaches the anterior edge of the eye disc $10 \mathrm{hr}$ after pupation and rough protein was detectable at the anterior margin of a 40 -hr pupal retina, the minimum time that rough protein was detectable in R2, R3, R4, and R5 is $30 \mathrm{hr}$. Furthermore, the posterior half of the 40-hr pupal retina did not contain detectable levels of rough protein. The cells at the midpoint of the pupal retina, where rough protein fell below detectable levels, began expressing rough protein in the morphogenetic furrow of a wandering third-instar larva 10-20 hr prior to pupation. This suggests an upper limit of 50-60 hr for rough protein expression in R2, R3, R4, and R5. Saint et al. (1988) performed in situ hybridizations with the homeo box-containing exon of the rough gene as probe on frozen sections of third-instar larvae and detected transcripts in both the eye disc and the larval brain. We have looked extensively for rough protein expression in the larval brain with MAbrol and have not detected any staining. The reason for this discrepancy is currently unknown.

periments, however, do not address the question of the position of rough in the hierarchy of genes that are necessary to form functional R2 and R5 cells; that is, what is the nature of the genes controlled by rough? The rough protein might control just the generation of the postulated inductive signal. At the other extreme, rough might control all aspects of R2 and R5 that differentiate them from the other photoreceptor cells. In this paper we have attempted to resolve this issue. First, we demonstrate that rough protein expression is restricted to a subset of cells in the developing eye imaginal disc of the third instar larva and early pupa. Knowledge of the wildtype pattern of rough expression has allowed us to design and interpret experiments in which rough is ectopically expressed. In this way we have been able to examine which properties of R2 and R5 can be conferred on another cell by rough expression. We find that rough expression directed by the sevenless promoter results in the transformation of the central R7 photoreceptor into a cell resembling R2 and R5 and the other outer photoreceptors. However, ectopic rough expression in the R7 precursor cannot bypass the requirement for sevenless 
function for this cell to undergo neural development. These results suggest that rough acts after a cell has been instructed to become a photoreceptor to specify the type of photoreceptor it will become. General expression of rough under the control of the $h s p 70$ promoter revealed another aspect of the specificity of rough action. Tissues outside the eye appear to be relatively unaffected by ectopic rough expression. Interestingly, we find that ubiquitous rough expression in the developing eye disrupts the progression of the morphogenetic furrow across the eye disc.

\section{Results}

rough protein is expressed only in the eye disc

Polyclonal and monoclonal antibodies against the rough protein were generated (see Materials and methods) and used to determine the pattern of rough protein expression during development of the eye imaginal disc. Figure 1A shows the typical nuclear staining pattern seen at the light microscope level when either polyclonal or monoclonal antibodies were used in histological preparations of late third-instar larval eye discs. The specificity of the monoclonal antibody rol (MAbrol) is demonstrated in the inset of Figure 1A, which shows that an eye disc from a third instar larva carrying a loss-of-function rough allele $\left(\mathrm{ro}^{\mathrm{x} 63}\right)$ did not stain with MAbrol. The pattern of rough protein expression has two components. First, rough protein is expressed broadly in the morphogenetic furrow where few, if any, unstained nuclei could be observed. The most anterior rough expression appeared to precede expression of the neuronal antigen recognized by MAb22C10 (see Tomlinson and Ready 1987a). Within the morphogenetic furrow, clusters of nuclei were observed that stained with MAbrol and that were spaced with the regularity of ommatidial preclusters. Often, seven nuclei that stain with MAbrol could be seen in the apical region of these clusters (Fig. $1 C, D)$. At this time, the R8 precursor is just beginning its neural differentiation. Although the identity of the cells that express rough in the morphogenetic furrow is difficult to determine, the simplest interpretation of this staining pattern is that the nuclei of the future R2, R3, R4, R5, and R8 cells and the two mystery cells (Tomlinson et al. 1987) M1 and M2 stain with MAbrol. Double-labeling experiments with the DNA stain Hoechst 33258 and MAbrol suggest that some cell nuclei located in the basal regions of the morphogenetic furrow do not stain with MAbrol (data not shown). The second component of rough expression begins at $\sim 6 \mathrm{hr}$ of ommatidial development, when rough protein expression becomes refined to four cells in each ommatidium (Fig. 1E-G). The nuclear positions and movements observed in these four cells identified them as photoreceptor precursors R2, R3, R4, and R5 (see Tomlinson 1985).

Figure 1B shows that rough protein was still detectable in cells at the anterior margin of a 40 -hr pupal retina. Most ommatidia near the anterior margin of the
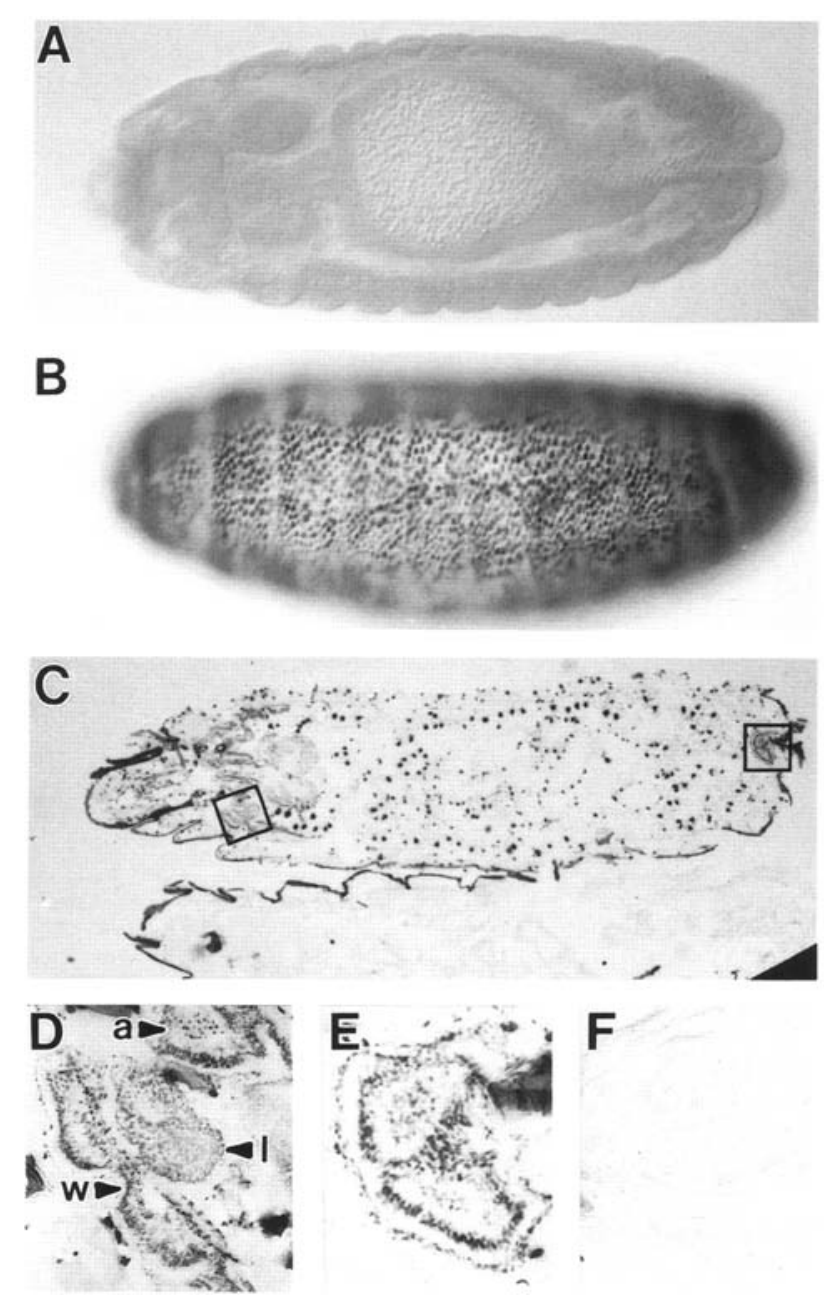

Figure 2. Ubiquitous rough protein expression is induced in all tissues after heat shock of transgenic embryos and larvae carrying a rough minigene under the control of the $h s p 70$ promoter. $A$ and $B$ are Nomarski images; $C-F$ show bright-field light micrographs. (A) Wild-type embryos did not stain with the anti-rough MAbrol. (B) MAbrol stained all nuclei of an embryo that carried a hsro construct $1-2 \mathrm{hr}$ after a 45 -min heat shock. (C) All nuclei in a transgenic hsro, ro ${ }^{\mathrm{x} 63}$ third-instar larva stained with MAbrol 1-2 hr after a 45-min heat shock. For comparison, a $r O^{\times 63}$ larva, which was heat-shocked and stained on the same slide as the top larva, is shown at bottom. $(D)$ Enlargement of the area boxed near the anterior of the hsro, ro ${ }^{x 63}$ larva shows that all nuclei in a leg disc (1), a wing disc $(w)$, and an antennal disc (a) stained with MAbrol. (E) All nuclei of the genital disc also stained with MAbrol, as can be seen in the enlargement of the tissue boxed at the posterior end of the hsro, $r O^{x 63}$ larva. $(F)$ The nuclei of imaginal discs in the $r 0^{x 63}$ larva do not stain with MAbrol. Magnification, $140 \times(A$ and $B) ; 20 \times$ $(C) ; 100 \times(D$ and $F) ; 150 \times(E)$.

pupal retina maintained the same expression pattern as the posterior regions of the larval eye disc (see Fig. 1B, inset). However, in some clusters only three photoreceptor precursor cells $(\mathrm{R} 2, \mathrm{R} 3$, and R5) stained with MAbrol. Tomlinson et al. (1988) did not detect transcripts from the rough gene in adult head mRNA. This evidence, coupled with the waning expression of protein 

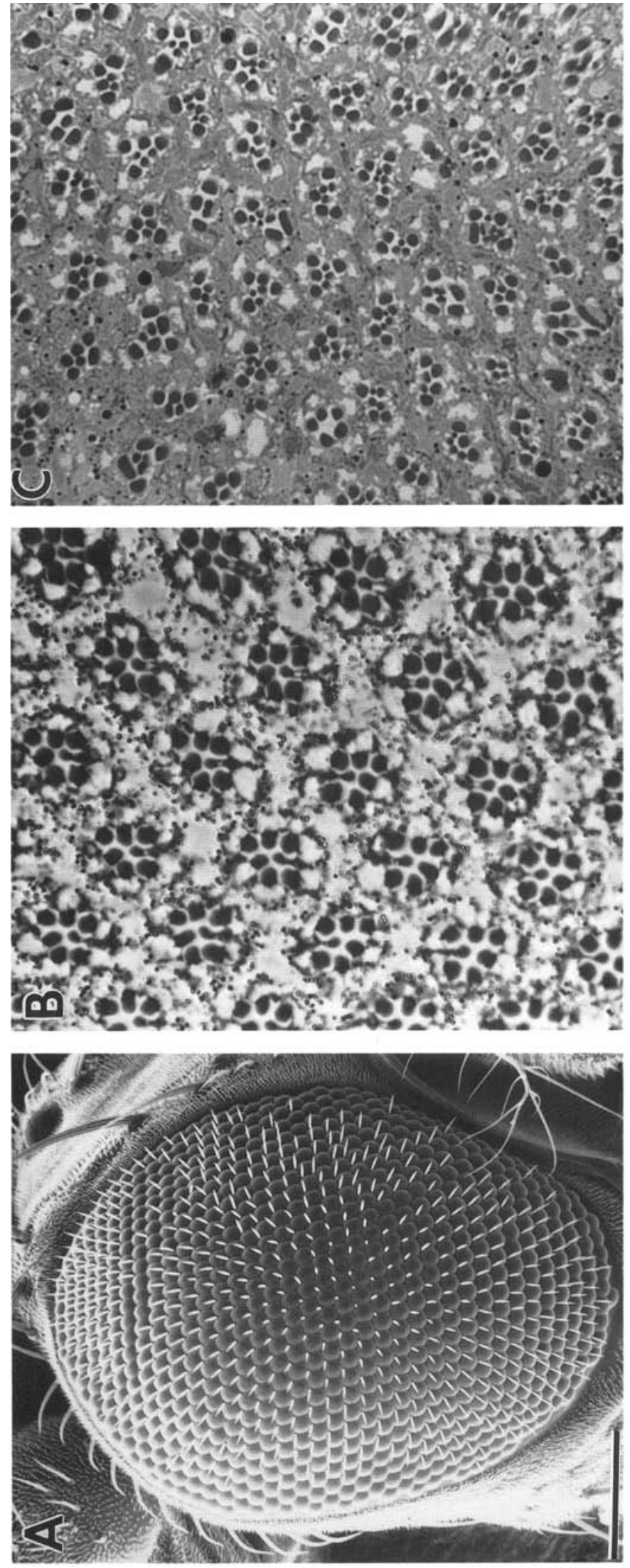
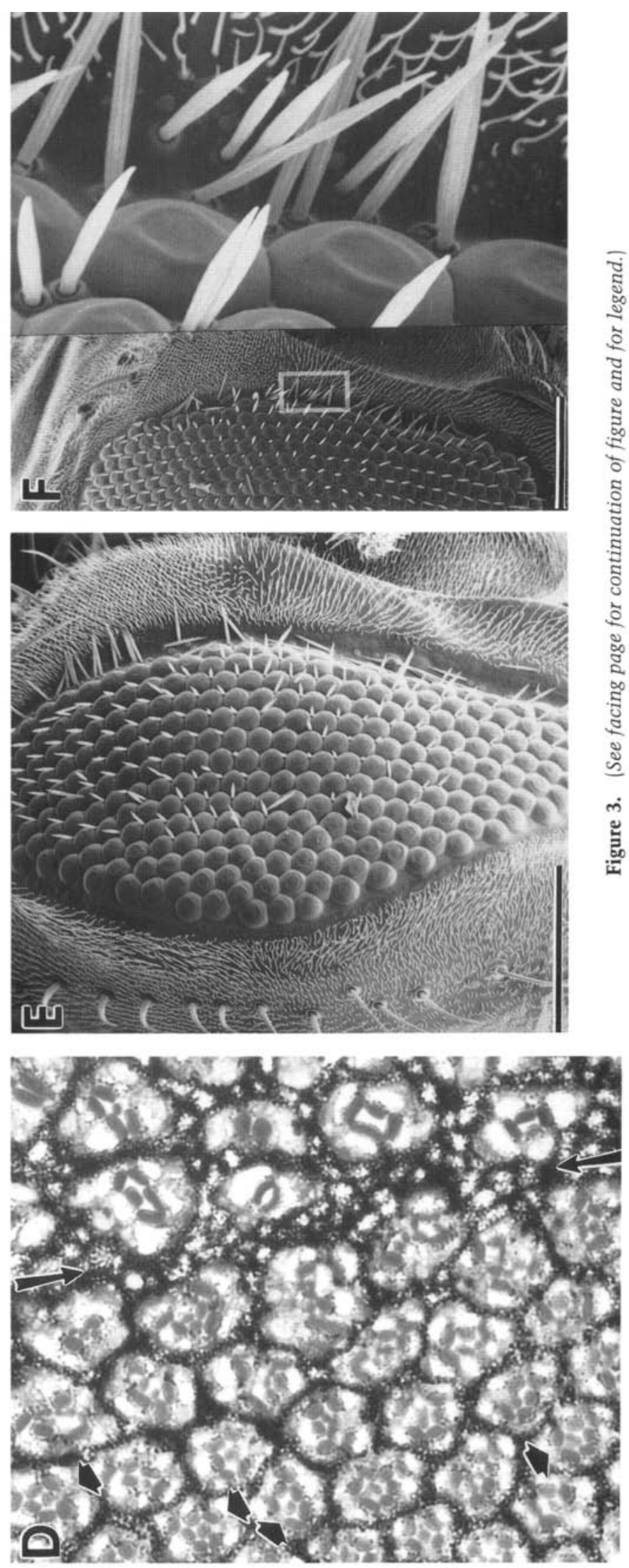
Kimmel et al.
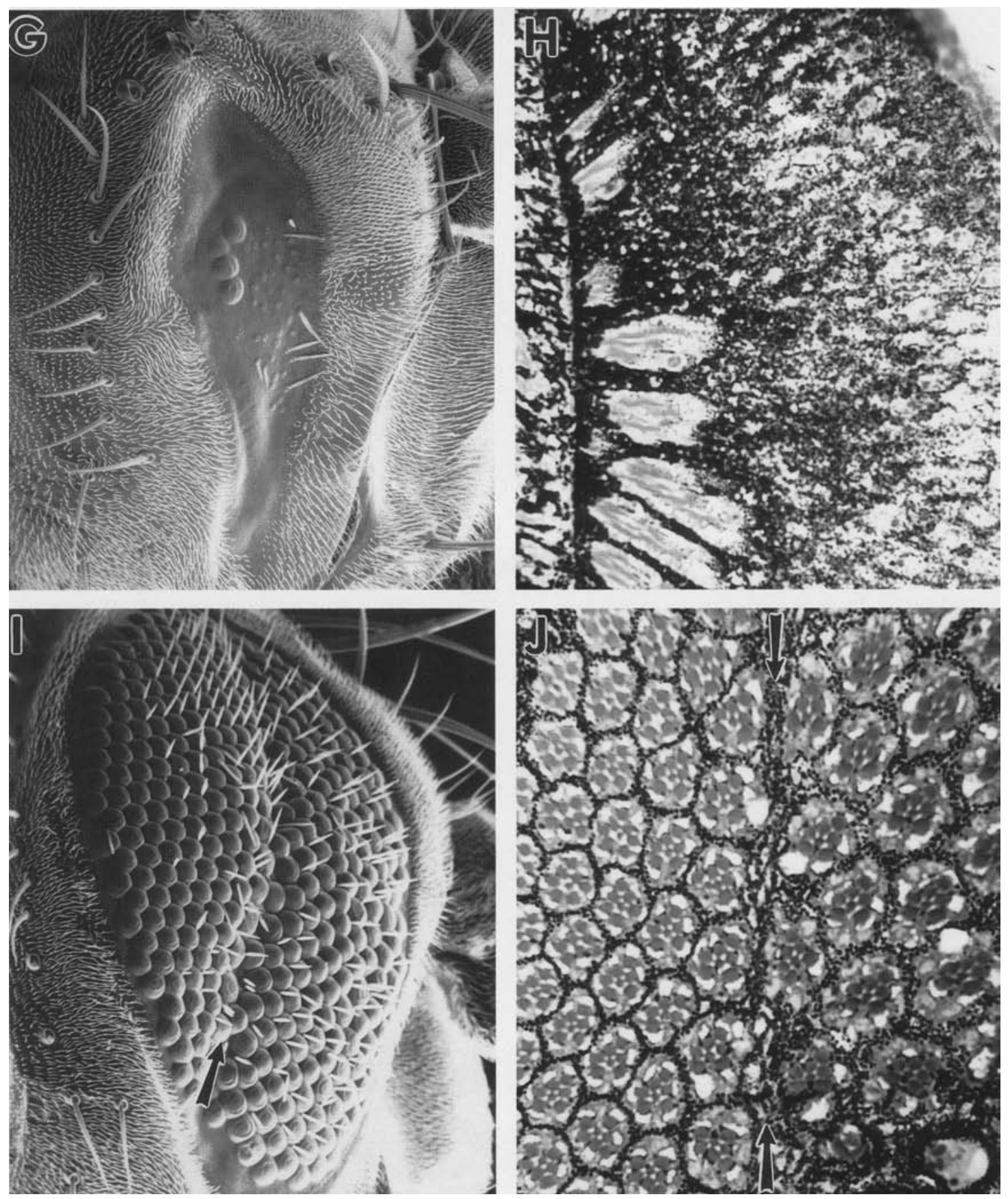

Figure 3. Ubiquitous rough expression during eye imaginal disc development alters adult eye morphology. $(A, E, F, G$, and $I)$ SEMs; $(B, C, D, H$, and $J)$ light micrographs of tangential sections through eyes of adult flies transformed with a construct in which rough expression is under the control of the $h s p 70$ promoter ( $h s r o)$. Anterior is to right. $(A$ and $B)$ Flies bearing the hsro construct showed normal eye morphology in the absence of heat shock. (C) A section through the eye of a genetically rough $\left(\mathrm{ro}^{\mathrm{x} 63}\right)$ null $\mathrm{fly}$. Wild-type ommatidia were not observed in the absence of rough function. $(D)$ Heat-shock-induced rough expression in mid third-instar larvae that are homozygous for $r^{x 63}$ allowed several ommatidia posterior of the scar (long arrows) to develop normally (wide arrows), as judged by their morphology in serial sections. However, the orientation of some of these ommatidia was abnormal. $(E)$ When $90-$ min heat shocks were given at $8-\mathrm{hr}$ intervals, beginning with mid to late third-instar larvae carrying the hsro construct, the size of the eye was reduced to approximately two-thirds its normal size. $(F)$ An increased number of bristles was observed at the position where eye development stopped. $(G$ and $H$ ) If heat shock pulses were started during the early third-instar larval, the size of the eye was reduced dramatically. The remaining tissue was rich in pigment granules $(H)$. (I) A single heat shock during the mid to late third-instar larval period resulted in a fly bearing a scar (arrow) through approximately the middle of the eye. Anterior to the scar, the eye had a slightly roughened appearance, although individual ommatidia had normal morphology ( $J$, anterior to the arrow). Ommatidia with mutant construction were often observed along the edge of the scar. The scar itself contained mostly pigment cells. Ommatidia anterior to the scar were spaced farther apart such that fewer ommatidia occupied the same area as those posterior to the scar. Bar, $100 \mu(A) ; 100 \mu$ $(E, G$, and $I) ; 100 \mu$ on the left and $10 \mu$ on the right $(F)$. 
seen in the pupal retina, argues that rough protein is not present in the adult photoreceptors. In sum, rough protein is detectable in the nuclei of the developing photoreceptors R2, R3, R4, and R5 for 30-60 hr.

MAbrol was used to determine whether rough protein is expressed in other tissues during development. rough protein was not detectable in histological preparations of whole-mount wild-type embryos (Fig. 2A), even though rough protein was easily detected after heat shock in transgenic embryos containing a rough minigene driven by the $h s p 70$ promoter (Fig. 2B; Materials and methods). Similarly, when frozen sections from wild-type late third-instar larvae were stained with MAbrol, only the eye imaginal disc tissue contained detectable amounts of rough protein (data not shown). We conclude from these results that rough protein expression is restricted to ommatidial precursor cells in the developing retina.

\section{Ubiquitous rough expression stops the progression of the morphogenetic furrow}

Analysis of somatic mosaics has shown that rough is required in the precursors of only two of the eight photoreceptor cells, R2 and R5, for normal ommatidial assembly to occur (Tomlinson et al. 1988). Our present study of rough protein expression shows that although rough is expressed in more than just these two cells, it is restricted temporally and spatially to a small number of cells in the developing eye. We asked whether ectopic expression of rough in other tissues and in other ommatidial precursor cells would interfere with their normal development. The $h s p 70$ promoter was fused to a rough minigene in the 5 '-untranslated leader, creating a heatinducible rough gene capable of expressing rough protein in every cell (see Materials and methods). The heat shock rough construct (hsro) was then introduced into flies by P-element-mediated transformation. Transgenic fly lines containing hsro in wild-type and $r 0^{x 63}$ genetic backgrounds were established, and various stages of the life cycle were subjected to heat pulses at $37^{\circ} \mathrm{C}$. Figure 2 , B-F, shows that rough protein was detectable in every embryonic and third-instar larval tissue after a single heat shock at $37^{\circ} \mathrm{C}$. Protein immunoblots of cephalic complexes dissected from transgenic third-instar larvae after heat shock showed that the hsro construct produces a protein of the correct molecular weight (data not shown).

Induction of rough protein during embryonic development reduced embryo viability. A single $60-\mathrm{min}$ heat shock administered at various times during embryogenesis reduced hatching by $\sim 30-50 \%$ compared to $10-20 \%$ observed with wild-type control embryos. Heat shocks administered during the three larval instars and the first half of pupal life did not affect viability significantly. However, multiple heat shocks during the second half of pupal life reduced viability by $\sim 40 \%$. No visible defects were observed in adult flies that developed from heat-shocked embryos, first- and second-instar larvae, or pupae. However, the eyes of adult flies containing the hsro construct that were heat-shocked as third-instar larvae showed severe defects; the other tissues of these flies appeared normal. A single $90-\mathrm{min}$ heat shock of late third-instar larvae or prepupae containing hsro resulted in a reduction in the size of the eye (see Fig. 3E). Closer inspection of this aberrant eye revealed that the anterior third of the retina was missing. If 90-min heat shocks were performed every $8 \mathrm{hr}$ on transgenic hsro larvae during third-instar larval development, the eyes of the resulting adults were almost completely devoid of facets (Fig. 3G) and contained very few photoreceptor cells (Fig. 3H). In contrast to these reduced eye phenotypes, a single heat shock applied to transgenic mid to late third-instar larvae resulted in a prominent scar near the middle of the eye (Fig. 3I,J). Normally constructed ommatidia were observed on both sides of the scar, although ommatidial spacing was abnormal anterior of the scar.

We have also examined the effects of ectopic rough expression in a rough mutant background; this analysis showed that the hsro construct makes functional rough protein capable of partially rescuing the rough phenotype. Figure 3D shows the result of a single 45-min heat shock of a transgenic hsro third-instar larvae that is genetically $r O^{\mathrm{x} 63}$. Anterior of the scar, the eye resembled that seen in rough mutants (Fig. $3 \mathrm{C}$ ); posterior of the scar, where ommatidial assembly was in progress at the time of the heat shock, partial rescue of the rough phenotype could be seen. Ommatidia posterior to the scar contained more photoreceptor cells, on average, than the typical rough ommatidia anterior to the scar $\mid 6.0 \pm 0.97$, $n=122$ vs. $4.7 \pm 1.1, n=119$ |. In addition, some wildtype ommatidia were seen in the region posterior to the scar (wide arrows); such morphologically wild-type ommatidia are not observed in sections of $r O^{\times 63}$ eyes (Fig. $3 \mathrm{Cl}$.

To determine why ubiquitous rough expression caused the various phenotypes described above, eye imaginal discs from wild-type larvae, carrying the hsro construct, were examined for developmental defects. Larvae were given a single 90 -min heat shock at $37^{\circ} \mathrm{C}$, and their eye discs were stained with MAbrol after 2, 6, 12,24 , or $36 \mathrm{hr}$ of recovery at $23^{\circ} \mathrm{C}$. Two hours after heat shock, high levels of rough protein were detected in every nucleus in the eye-antennal disc (Fig. 4B). Protein originating from the hsro construct was substantially reduced $6 \mathrm{hr}$ after the heat shock, and the wild-type rough expression pattern began to stand out from the background of protein remaining from the hsro induction (Fig. 4C); however, the normally intense expression of rough protein in the morphogenetic furrow was greatly reduced (cf. Fig. 4A with C and D). Examination of MAbrol-stained eye discs 12 and $24 \mathrm{hr}$ after heat shock revealed that rough protein was completely absent from the morphogenetic furrow; yet, posterior of the furrow, rough protein was easily detectable (Fig. $4 \mathrm{E}, \mathrm{F}$ ). The observed expression pattern, however was subtly abnormal because ommatidial clusters near the furrow appeared to be developmentally older than ommatidia that normally would occupy this position in the eye disc.

Tomlinson and Ready (1987a) have demonstrated that 
Kimmel et al.

Figure 4. Effects of ubiquitous rough expression on eye disc development. Ubiquitous rough protein expression was induced by heat shock in transgenic larvae that carry a rough minigene fused transcriptionally to the $h s p 70$ promoter (hsro). Whole-mount discs from late third-instar larvae were observed by light microscopy after being stained with the anti-rough MAbrol $(A-G)$ or with MAbBP104 $(H-N)$, which stains all Drosophila neurons (Hortsch et al. 1990). The arrowheads mark the position of the morphogenetic furrow (MF). Anterior is to right. $(A-C)$, Magnification, $\sim 100 \times ; \sim 1300 \times(D-N)$. Larvae were heat-shocked for $90 \mathrm{~min}$ at $37^{\circ} \mathrm{C}$, and the discs were stained after $2,6,12,24$, or $36 \mathrm{hr}$ of recovery at $23^{\circ} \mathrm{C}$, as indicated by the numbers in $B-G$ and $I-N$ (upper right). (A) The normal pattern of rough expression was observed in the hsro larvae in the absence of heat shock. $|B|$ rough protein was found at high levels in all cells $2 \mathrm{hr}$ post-heat shock (C) After $6 \mathrm{hr}$, rough protein could still be detected in all cells, but the levels were significantly higher in photoreceptor cells R2, R3, R4, and R5. $(D-F)$ Between 6 and $24 \mathrm{hr}$ after heat shock, cells in the MF did not express rough protein. Developing ommatidia located just posterior to the MF showed morphological properties typical of more mature ommatidia that are normally located several rows posterior of the MF. (G) A second MF (wide arrow), with an apparently normal rough expression pattern, was observed in discs that were allowed to recover for $36 \mathrm{hr}$ after heat shock. Using Nomarski differential interference contrast, two dorsoventral indentations were observed in these discs: one at the position of the arrested furrow and one at the position of the new MF. $(H-L)$ MAbBPl04 stains developing photoreceptor precursor cells in the same sequential order as does MAb22C10 (Tomlinson and Ready 1987a; B. Kimmel and U. Heberlein, unpubl.|. Discs from hsro larvae stained with MAbBP104 in the absence of $(H)$ or various times after $(I-L)$ the heat shock showed that ommatidia located immediately posterior to the MF continued differentiating normally after the heat shock. $(H)$ Staining in the R8 precursor was observed in the first row posterior to the MF in discs that were not heatshocked. (I-L) Cell pairs R2/5, R3/4, R1/6 and, finally, R7 were added sequentially to these clusters next to the MF between 2 and $24 \mathrm{hr}$ after heat shock. $(M)$ A basal view of the disc shown in $L$ revealed that axon bundles were growing from the ommatidia just posterior of the MF toward the optic stalk. (N) A new MF (wide arrow) was also observed in MAbBP104-stained discs $36 \mathrm{hr}$ after heat shock. A stripe of cells between the new MF and an indentation at the position of the arrested MF did not appear to express either rough $(G)$ or neuronal antigens $(N)$. In the MAbBP104-stained disc $(N)$, two to three columns of ommatidia had been laid down posterior to the new furrow. Therefore, $\sim 4-6 \mathrm{hr}$ had passed since the new furrow reinitiated the ommatidial differentiation process. On the basis of this calculation, a single pulse of ubiquitous rough expression prevents the ommatidial assembly processes from occurring for $\sim 30 \mathrm{hr}$ at $23^{\circ} \mathrm{C}$. (This number has not been corrected for the developmental delay caused by heat shock in both wild-type and hsro individuals.)

the photoreceptor cells differentiate in a sequential pattern. This sequence was easily visualized after staining eye discs with MAbBP104 (Bieber et al. 1989; Hortsch et al. 1990; B. Kimmel and U. Heberlein, unpubl.), which recognizes the neuron-specific form of Drosophila neuroglian. The developmental stage of an ommatidium can be assessed by determining the number and arrangment

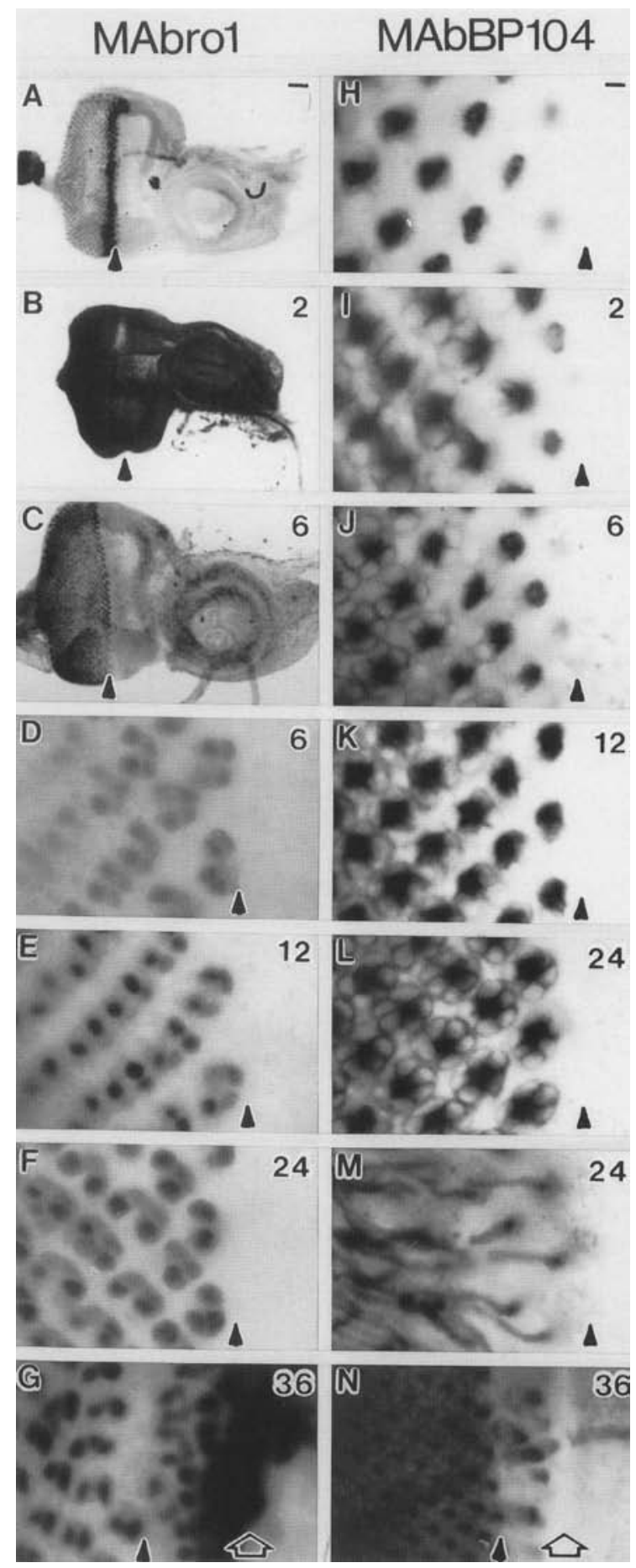

of photoreceptor precursors that have neuronally differentiated in that cluster. Analysis of MAbBP104-stained eye discs from transgenic hsro larvae 2, 6, 12, and $24 \mathrm{hr}$ after a 90-min heat shock showed that no new ommatidial clusters were formed in the morphogenetic furrow after the heat shock (Fig. 4I-M). Nevertheless, the column of ommatidia just posterior to the furrow con- 


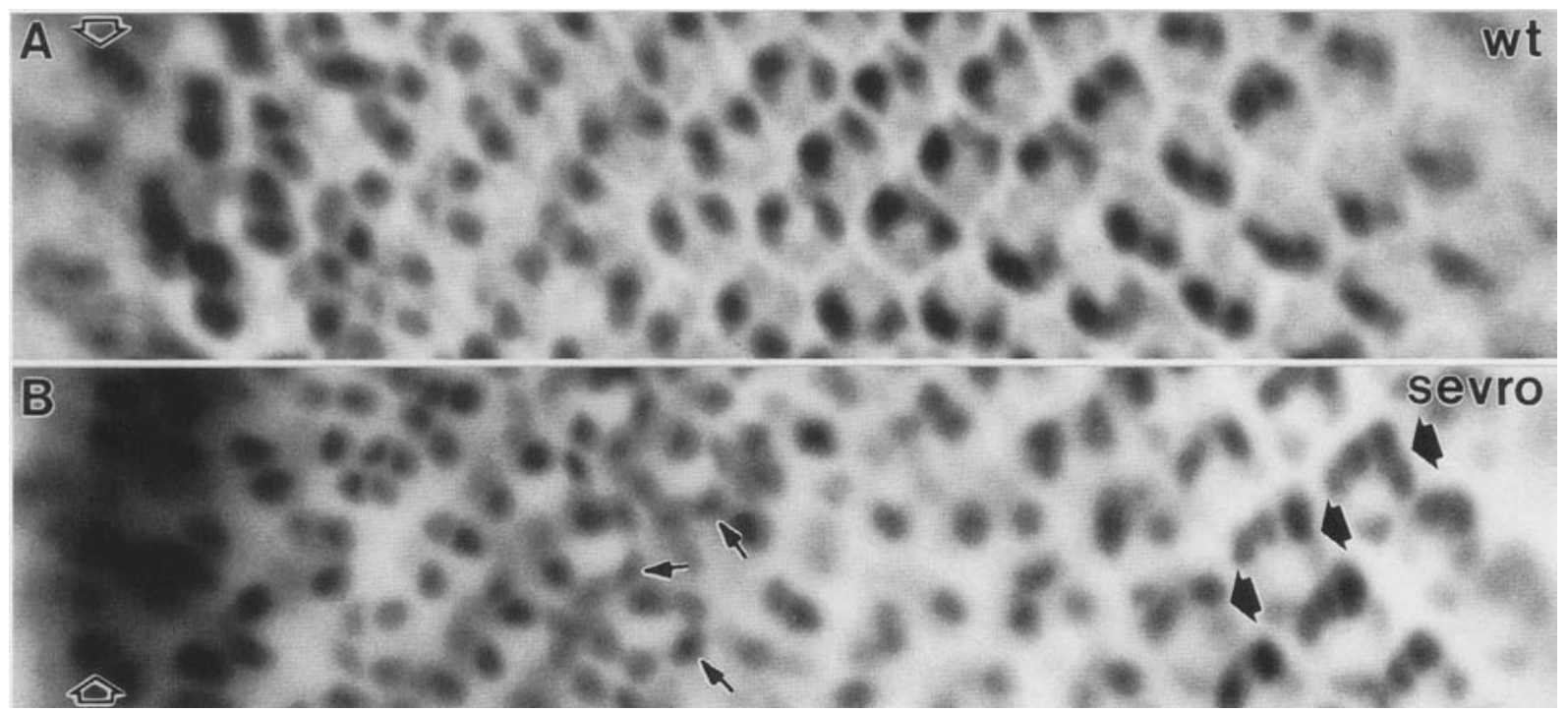

Figure 5. Expression of rough protein in eye imaginal discs from transgenic larvae containing a rough minigene driven by the sevenless promoter. Late third-instar larval eye discs were stained with MAbrol and observed as whole-mount preparations by light microscopy. The morphogenetic furrow is marked by the open arrows, posterior is to right. Magnification, $1500 \times$. (A) Wild-type eye $\operatorname{disc}_{;}(B)$ eye disc from a larva bearing a rough minigene fused transcriptionally to the sevenless gene promoter (sevro). The transgenic sevro larva has a wild-type genetic background, so the observed staining is a combination of the sevenless promoter-directed and the normal rough expression patterns. All aspects of the sevenless expression pattern were observed in eye discs that contain the sevro construct. For example, the small arrows point to R7 precursor cells that expressed rough protein from the sevro construct. The wide solid arrows identify ommatidial clusters where all four cone cells were expressing rough protein. The intensity of MAbrol staining observed in the R7 and cone cell precursor cells was always less than the strong staining normally observed in cells occupying the morphogenetic furrow and approximately equal to the level of staining seen in R2 and R5 posterior to the morphogenetic furrow.

tinued to develop such that $24 \mathrm{hr}$ after heat shock, these clusters contained eight photoreceptor neurons that had sent out axons toward the optic stalk (Fig. $4 \mathrm{~L}, \mathrm{M}$ ). Although ubiquitous rough expression in the eye disc caused the morphogenetic furrow to stop its anterior progression for at least $24 \mathrm{hr}$, examination of discs $36 \mathrm{hr}$ after the heat shock demonstrated that the ommatidial assembly process could reinitiate (Fig. $4 \mathrm{G}, \mathrm{N}$ ). A new morphogenetic furrow (wide arrow), where rough is expressed in the normal pattern (Fig. 4G), was evident in these discs. Posterior to this new furrow, new ommatidial clusters have begun to assemble (Fig. 4N).

The adult eye phenotypes described above can be explained on the basis of the data obtained from the eye disc experiments. First, the extreme no-eye phenotype (Fig. 3G) results from continuous ubiquitous rough expression that blocks the initiation of ommatidial assembly. Second, a single heat shock in late larval life causes the furrow to stop, but the larvae then pupate before the ommatidial assembly process can restart, generating the reduced eye phenotype shown in Figure 3E. Finally, a single pulse of rough protein in mid to late third-instar larvae stops the furrow from advancing for $\sim 30 \mathrm{hr}$, after which reinitiation of the ommatidial assembly process occurs, and additional retina tissue differentiates (Fig. 3I). A scar is seen in the middle of these eyes corresponding to the approximate position of the morphogenetic furrow at the time of the heat shock. rough expression in the $R 7$ cell precursor transforms $R 7$ into a R1-6 photoreceptor cell type

As shown above, general ectopic rough expression has profound effects on Drosophila eye development. However, analyses using the hsro construct are limited in that rough expression can only be delivered in heat-induced pulses to every cell. To determine the effects of ectopic rough expression in individual ommatidial precursor cells, the sevenless promoter was fused to the rough minigene to generate the construct sevro (see Materials and methods|. The sevenless promoter generates a dynamic pattern of protein expression that is restricted to a subset of ommatidial precursor cells posterior to the morphogenetic furrow in the eye imaginal disc (Tomlinson et al. 1987; Basler et al. 1989; Bowtell et al. 1989): first in the mystery cells (see Tomlinson et al. 1987) and in R3 and R4, very transiently and at low levels in R1 and R6 and then in R7, and finally in the four cone cells. All aspects of this expression pattern were seen in eye discs from transgenic sevro larvae stained with MAbrol; in larvae that carry a wild-type rough gene, a summation of the sevro-directed and wild-type rough expression patterns was observed (Fig. 5). In such larvae, rough is ectopically expressed at high levels in a single photoreceptor cell type, R7, and in the four cone cells.

To determine whether the ectopic rough expression generated by sevro has an effect on eye development, 

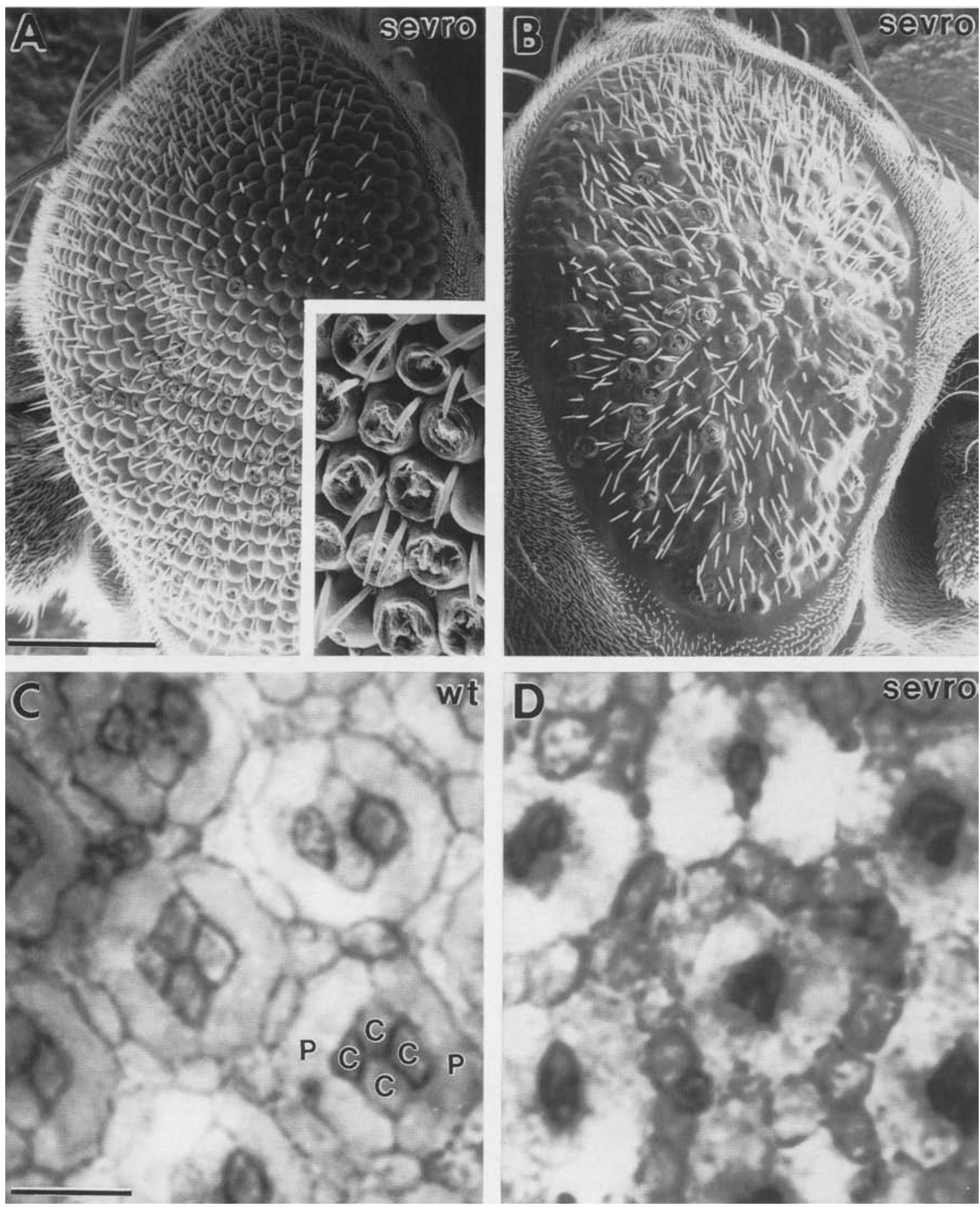

Figure 6. Ectopic rough expression using the sevenless promoter disrupts eye morphology and cone cell development. The eyes of transgenic adult flies, which contain a transcriptional fusion between the sevenless promoter and a rough minigene (sevro), were examined for defects by SEM. (A) Micrograph of an eye from an adult fly that has two copies of the sevro construct in its genome. Facets that had abnormal lens structures (inset) and minor disnuptions in the patterning of ommatidia were evident. (B) In flies carrying four copies of sevro, normal corneal lenses were no longer observed. $(C$ and $D)$ As seen in these light micrographs, ectopic rough expression in the cone cells alters their morphology in 44-hr pupal retinas. $(C)$ The apical surface of the pupal retina can be stained with cobalt sulfide, revealing the regular wild-type pattern of assembling accessory cells (Cagan and Ready 1989). The four centrally located cone cells are surrounded by two primary pigment cells that are, in turn, surrounded by a host of secondary and tertiary pigment cells as well as by bristle-producing cells. The cone $(C)$ and primary pigment $(P)$ cells are labeled in one of the ommatidia shown. $(D)$ The cone cells in 44-hr pupal retinas from pupae carrying two copies of sevro had reduced apical projections. Moreover, some ommatidia appeared to have fewer than four cone cells, and defects in pigment and bristle cell organization and number were also seen. $\operatorname{Bar}, 100 \mu(A$ and $B) ; 10 \mu(C$ and $D)$. 
adult eyes, pupal retinas, and eye imaginal discs from sevro transgenic fly lines were analyzed. Thirteen of the 14 transformant lines, for which it was possible to generate homozygous flies, showed some visible external phenotype in the adult eye. This external phenotype was not seen in flies that contain only one copy of the sevro construct; however, defects were visible in eye sections of such flies. The different transformant lines varied in phenotype severity; however, for each line, the phenotype was more pronounced in flies carrying two or more copies of the sevro construct, arguing that the level of rough protein produced was within the phenocritical range. A scanning electron micrograph (SEM) of a typical eye from a fly carrying two copies of sevro is shown in Figure 6A. Many of the corneal lenses in this eye had altered morphology (Fig. 6A, inset). As more copies of sevro were added to the fly's genome, the external phenotype became progressively more extreme. For example, flies with four copies of the sevro construct developed eyes with grossly altered morphology, as shown in Figure 6B. These eyes had few, if any, ommatidia with normally constructed corneal lenses.

The corneal lenses are produced by the four cone cells, which cover the eight photoreceptor cells in an adult ommatidium (see Fig. 7D). The external eye phenotype observed in adult flies containing the sevro construct suggests that the fate of the cone cells has been altered by ectopic rough expression. We examined 44-hr pupal retinas from wild-type (Fig. 6C) and sevro (Fig. 6D) animals after staining the retinas with cobalt sulfide to highlight the apical projections of cells. By this stage of eye development, ectopic rough expression had clearly disrupted the differentiation of the sevro cone cells, and their apical projections were much smaller than those of wild-type cone cells (cf. Fig. 6C and D). Furthermore, some ommatidial clusters appeared to have fewer than four cone cells, and defects in primary pigment and bristle cell organization and number were also seen. The ultimate fate of these abnormal cone cells is unknown. The defects observed in cone cell development are most likely a result of sustained ectopic expression of rough in the cone cells. However, it is formally possible that other aspects of rough misexpression in sevro transformant lines may contribute to the observed cone cell defects. To determine whether sevro alters ommatidial assembly at earlier stages of eye development, eye imaginal discs from sevro larvae were stained with MAbBP104, which stains all Drosophila neurons. No defects were observed in these eye discs (data not shown).

Ectopic expression of rough protein from the sevro construct also altered the normal internal morphology of the adult eye. Figure 7A shows an apical cross section through the eye of a fly carrying two copies of the sevro construct. A total of 1104 facets were examined for defects in sections from 12 heads that originated from six different transformant lines homozygous for a single sevro insert. The most common form of ommatidium seen in these eyes contains eight photoreceptor cells, seven of which have outer photoreceptor cell mor- phology. This type of ommatidium made up between $31 \%$ and $91 \%$ (average $56 \pm 18 \%$ ) of the eye, depending on which transformant line was examined; wild-type ommatidia comprised 3-50\% (average $26 \pm 14 \%$ ). Ommatidia that contained too few or too many photoreceptor cells (average $18 \pm 7 \%$ ) were also observed. Closer examination of the predominant ommatidial structure in the sevro eye revealed that the cell occupying the R7 photoreceptor position had been transformed into a R 1-6 photoreceptor type. Normally, both the R7 and R8 photoreceptor cells produce smaller lightharvesting organelles, called rhabdomeres, than the R1-6 cells, and the rhabdomeres of R7 and R8 are located in the center of the photoreceptor cluster (see Fig. $7 E, F)$. Moreover, the rhabdomeres of R1-6 cells span the depth of an ommatidium, whereas the R7-cell rhabdomere ordinarily occupies only the apical portion of the retina (see Fig. 7D). The R8 rhabdomere is positioned immediately under the R7 rhabdomere in the more basal part of the ommatidium. In contrast, tangential sections through the adult retina of a fly containing two copies of sevro revealed that the transformed R7 photoreceptor (R7T) produced a rhabdomere that did not project into the center of the ommatidium and had a diameter characteristic of R1-6 photoreceptors (cf. Fig. 7E and I). Sections taken at different levels of a sevro eye demonstrated that the rhabdomere of the R7T cell extended the depth of the ommatidium such that eight rhabdomeres were present in basal planes of section (see Fig. 7J). Finally, the nucleus of the R7T cell was located in the apical part of the retina where the nuclei of outer photoreceptor cells reside (data not shown). Therefore, the R7T photoreceptor possesses all of the morphological attributes of an R1-6 photoreceptor.

In addition to their morphological differences, the central and outer photoreceptors express different rhodopsins (O'Tousa et al. 1985; Zuker et al. 1985, 1987; Montell et al. 1987; Pollock and Benzer 1988); in particular, only the outer photoreceptor cells R1-R6 express the major Drosophila rhodopsin Rh1. To test whether R7T photoreceptors also express $\mathrm{Rh} l$, tangential sections of sevro retinas were stained with the anti-Rh1 monoclonal antibody MAbDRO4C5 (de Couet and Tanimura 1987). R7T photoreceptors stained brightly with this antibody (Fig. $7 \mathrm{~B}, \mathrm{~K}$ ), demonstrating that they express Rhl, whereas untransformed R7 cells and the more basally located R8 photoreceptors did not stain (see Figs. 7G,H,L). Wild-type R7 photoreceptors express either the $\mathrm{Rh} 3$ or Rh4 rhodopsin. The Rh4 promoter has been well characterized (Fortini and Rubin 1990) and Rh4-CAT (chloramphenicol acetyltransferase) transformants are available that express CAT specifically in R7 cells. When such a transformant line was crossed into a sevro background, the level of $\mathrm{Rh} 4$-promoter driven CAT activity was reduced to $12 \%$ that of wild-type controls. Thus, the rough-induced morphological transformation of the R7 cells is accompanied by a switch in the rhodopsin type expressed in these cells from R7-specific to R1-6-specific.

To test whether the transformation of the R7 photore- 


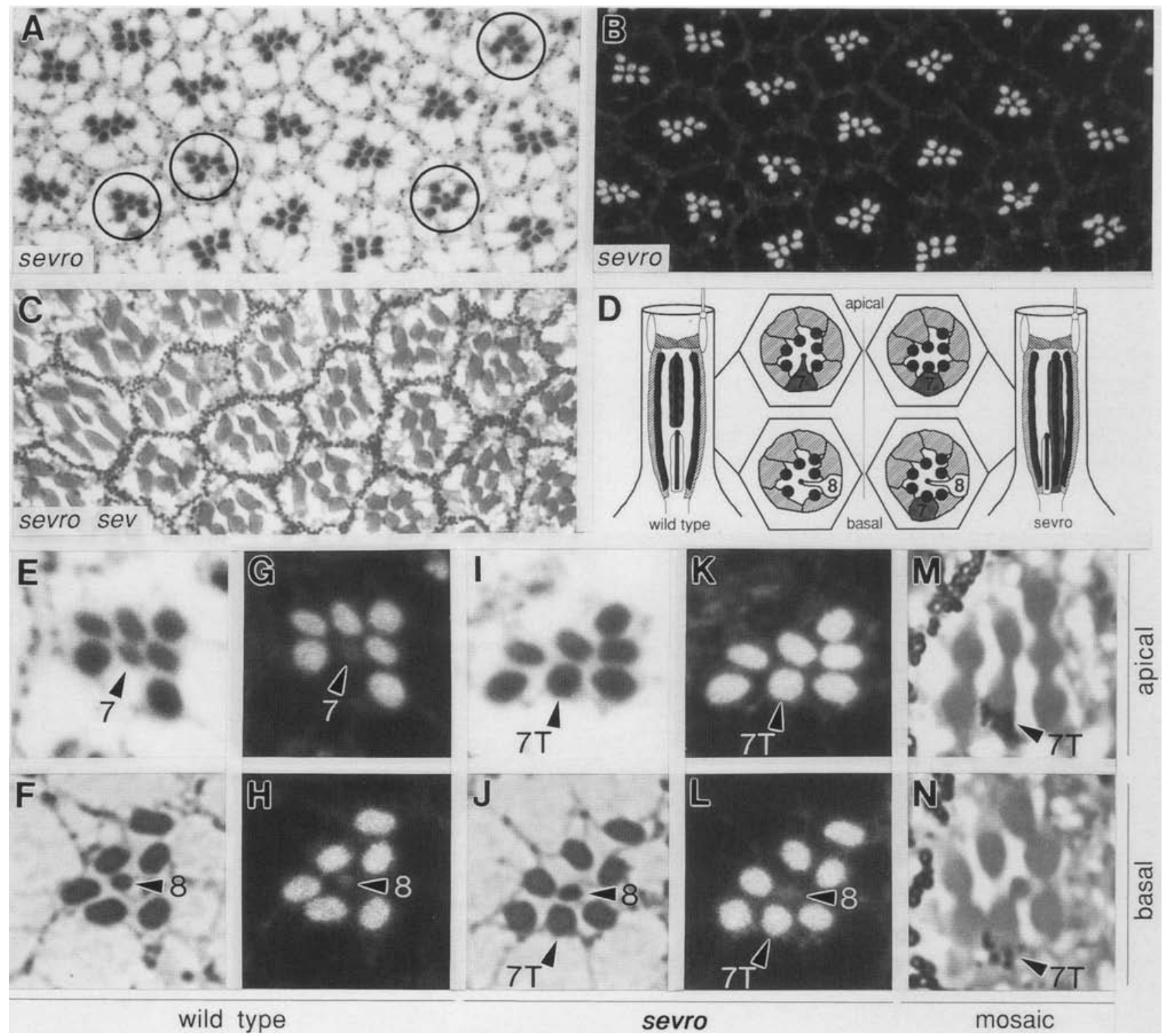

Figure 7. (See facing page for legend)

ceptor cell seen in sevro adult eyes results solely from ectopic expression of rough in the R7 precursor cell, itself, and not from secondary effects of rough expression in other cells, we analyzed mosaic ommatidia in which only a subset of cells contained the sevro construct. In serial sections from seven mosaic eyes, 52 mosaic ommatidia in which the $\mathrm{R} 7$ cell was transformed into an outer photoreceptor were observed. Cells carrying the sevro construct could be identified by pigmentation produced by a linked white ${ }^{+}$gene /see Materials and methods). In these mosaic ommatidia, the R7T cell was the only photoreceptor that always contained the sevro construct. The number of sevro- photoreceptors observed in each position of the 52 mosaic mutant ommatidia was as follows: R1 (5), R2 (27), R3 (26), R4 (29), R5 (27), R6 (11), R7 (0), R8 (20; for technical reasons 10 of the 52 R8 cells could not be scored). We observed three mosaic ommatidia in which only the transformed $\mathrm{R} 7 \mathrm{~T}$ cell contained the sevro construct. An example of such an ommatidium is shown in Figure 7, M and N. These data indicate that ectopic expression of rough in the R7 precursor cell, alone, can transform it into an outer photoreceptor cell.

In the wild-type ommatidial assembly process, the $s e$ venless gene is necessary for the $\mathrm{R} 7$ cell to differentiate into a photoreceptor (Harris et al. 1976; Campos-Ortega et al. 1979; Tomlinson and Ready 1987b); in the absence of sevenless, the R7 precursor cell develops into a nonneuronal cone cell (Tomlinson and Ready 1986). We asked whether ectopic rough expression in the R7 cell precursor would rescue the neuronal potential of the R7 precursor in the absence of sevenless function. A sev ${ }^{d 2}$, sevro fly stock was established, and sections through adult eyes were examined to determine the structure of ommatidia in this stock. As shown in Figure 7C, ommatidia in $\mathrm{sev}^{d 2}$, sevro flies lacked the R7 cell and therefore 
had only six rhabdomeres in the apical region of the eye. We conclude that rough is unable to bypass the requirement for sevenless function to specify neuronal fate in the $\mathrm{R} 7$ precursor cell.

The sevro construct was also crossed into a $r^{x 63}$ background to determine whether the expression of rough in a sevenless pattern could partially rescue the rough phenotype. A total of 211 ommatidia were examined from three eyes, which came from sevro, ${ } \mathrm{r}^{\mathrm{x} 63}$ adult flies. The average number of photoreceptors per ommatidium in these eyes was $4.9 \pm 1.2$, which is very similar to the number of photoreceptors found in $\mathrm{ro}^{\mathrm{x} 63} \mathrm{om}$ matidia. Therefore, rough protein expressed in the sevenless pattern does not partially rescue the rough phenotype. This is not surprising, because the sevro construct did not express detectable levels of rough in R2 and R5, the two cells in which rough function is known to be essential.

\section{Discussion}

Our analysis of the pattern of rough expression revealed that rough protein is restricted to nuclei in the devel- oping retina. Initially, rough is expressed in most, if not all, cells in the morphogenetic furrow. Although we cannot be certain of the identity of cells that express rough in the furrow, our analysis suggests that these cells include R2, R3, R4, R5, R8, and the two mystery cells $\mathrm{Ml}$ and M2. This broad pattern of rough expression is rapidly refined such that only R2, R3, R4, and R5 maintain detectable levels of the rough protein in the regions posterior to the morphogenetic furrow. Thus, there appear to be at least two separately controlled components to rough expression: one that produces the initial broad expression, and another that restricts rough protein to R2, R3, R4, and R5. In some respects, rough expression is reminiscent of the expression of other homeo domain-containing proteins in the embryo (for review, see Ingham 1988). Many of the homeo domain proteins involved in early embryonic development are first expressed in broad stripes of nuclei that are later narrowed as the segmental body plan of the embryo develops. The processes that refine the precellularization expression patterns of these homeo box genes are likely to be mechanistically different from those that regulate

Figure 7. Expression of rough in the R7 precursor cell transforms the R7 cell into an R1-6 cell. Tangential sections of adult retina, from flies of various genotypes, were prepared to examine the internal structure of ommatidia. (A) Light micrograph of a section through the apical region of an eye from an adult fly containing two copies of sevro. Ectopic rough expression in the R7 precursor cell has apparently transformed the R7 photoreceptor cell into an R1-6 photoreceptor type. The cell occupying the R7 position (R7T) in sevro eyes produced a rhabdomere that was not centrally located and was the same size as the rhabdomeres of the outer photoreceptors R1-R6. Some ommatidia in these eyes had wild-type construction (circled), showing that the phenotype caused by the sevro construct was not completely penetrant. [Abnormal ommatidia similar to those seen in these sevro sections were occasionally observed posterior to the scar in the eye of flies exposed to ubiquitous rough expression from the hsro construct (data not shown).] (B) Fluorescence micrograph of the same section shown in A stained with MAbDRO4C5, which recognizes the major Drosophila rhodopsin Rhl (de Couet and Tanimura 1987). The anti-Rhl antibody normally stains the rhabdomeres of only the six outer photoreceptor cells. However, the rhabdomeres of the R7T photoreceptors seen in $A$ clearly stained with the anti-Rhl antibody, whereas the normal R7 photoreceptors in the same field did not fluoresce above the background autofluorescence seen in the surrounding pigment cells. (C) Light micrograph of an apical section through a sevro eye that is in a sev ${ }^{d 2}$ background. The sevenless mutation causes the $\mathrm{R} 7$ photoreceptor precursor to develop into a non-neuronal cone cell. The R7T photoreceptor also required the sevenless gene product to differentiate into a neuron. Note that most ommatidia have only six rhabdomeres in the apical portion of the retina. However, $\operatorname{sev}^{d 2}$, sevro flies had eyes that were generally more disorganized than $\mathrm{sev}^{d 2}$, as the mild disorganization characteristic of sevro eyes (see text) was also seen in this stock. (D) The structure of the sevro ommatidium (right) is compared schematically in cross section to the structure of a wild-type ommatidium (left). Black shading represents the rhabdomeres, the R7 photoreceptor cell is shaded in gray, the $\mathbf{R} 8$ photoreceptor is unshaded, the outer photoreceptor cells are lightly crosshatched, and the heavy crosshatching highlights the cone cells that lie just above the photoreceptors. The cone cells produce the lens at the top of each ommatidium. The surrounding pigment cells are not shaded. Normally, the centrally located rhabdomeres of photoreceptors R7 and R8 lie one on top of the other. However, the rhabdomere of the R7T photoreceptor seen in sevro eyes extends to the basal boundary of the ommatidium, as do the rhabdomeres of the outer photoreceptor cells. Schematic tangential sections through the apical and basal regions of each ommatidial type are also shown. The R7 and R8 photoreceptors are labeled. The cell occupying the R7 position in sevro eyes produces a rhabdomere the size of those of the outer photoreceptors. $(E)$ Light micrograph of a section through a single wild-type ommatidium in the apical region of the retina. The arrow points to the centrally located $\mathrm{R} 7$ rhabdomere, which was smaller in size than the rhabdomeres of the six outer photoreceptor cells. $(F)$ A section through the basal region of the wild-type ommatidium shown in $E$. The R8 rhabdomere (arrow) had a similar size and location to the normal R7 rhabdomere. The rhabdomere of a wild-type R7 cell normally rests directly above the rhabdomere of the R8 photoreceptor so that only seven rhabdomeres are visible in any one plane of section through a wild-type ommatidium. ( $G$ and $H$ ) The sections shown in $E$ and $F$ were stained with the anti-Rh1 MAbDRO4C5 and visualized by fluorescence microscopy. The centrally located R7 and R8 rhabdomeres (arrows) did not stain with the anti-Rh1 antibody. (I) An apical section through a single ommatidium from a sevro eye showing the transformed R7 photoreceptor (7T). Examination of serial sections through sevro eyes revealed that the rhabdomere of the R7T photoreceptor spanned the depth of the ommatidium such that there were eight rhabdomeres rather than seven in the basal plane of section in the sevro ommatidium $(J)$. $(K$ and $L)$ The R7T rhabdomere stained brightly with the anti-Rhl antibody showing that the R7T photoreceptor expressed the major Drosophila opsin Rhl. The R8 rhabdomere in the basal plane of section (arrowhead 8 in $L$ ) did not stain with the Rhl antibody. $(M$ and $N$ ) The R7T transformation can occur when only the R7 photoreceptor carries the sevro construct. Apical $(M)$ and basal $(N)$ sections through a mosaic ommatidium (see Materials and methods) in which the transformed R7 cell (7T) was the only photoreceptor that carried the sevro construct. The sevro construct is linked to the $w^{+}$gene, which is necessary for the presence of pigment in photoreceptor cells. Thus, the presence or absence of the sevro construct could be scored on the basis of the presence or absence of pigment granules (arrowheads) next to the rhabdomeres. Magnification, $1000 \times(A-C) ; 2500 \times(E-N)$. 
rough because the signals to maintain or shut off rough expression must cross cell membranes in the ommatidial precursor cells. Among DNA-binding proteins, few have as restricted an expression pattern as rough. However, even this limited expression pattern appears to be more complex than necessary, because mosaic analysis (Tomlinson et al. 1988) indicates that the rough gene is required only in $\mathrm{R} 2$ and $\mathrm{R} 5$ for ommatidial assembly to proceed normally. rough protein is also present in the precursors to R3 and R4. From the mosaic analysis, we know that this expression is not required to produce an ommatidium with normal morphology. Thus, rough appears to have either a redundant function or no function in R3 and R4, although we cannot rule out a function whose disruption would not affect ommatidial morphology. Similarly, the available data do not suggest a function for the more general rough expression seen in the morphogenetic furrow.

We have demonstrated that restricted rough expression within the eye disc is necessary for normal eye development to occur. General ectopic rough expression interfered with the movement of the morphogenetic furrow across the eye disc and the initiation of ommatidial differentiation. Concordantly, continuous rough expression during third-instar larval and early pupal development resulted in the absence of retinal tissue. The progression of the morphogenetic furrow across the eye disc is not driven by ommatidial assembly, as furrow movement occurs in a mutation in which ommatidia do not form (Baker and Rubin 1989). This suggests that the failure of the morphogenetic furrow to advance after ectopic rough induction cannot be a consequence of the inability to initiate ommatidial differentiation under these conditions. Although overt differentiation is not observed anterior to the morphogenetic furrow, several genes have been shown to be expressed specifically in this region. For example, hairy, a member of the myc superfamily (Rushlow et al. 1989), is expressed in a stripe of cells anterior of the morphogenetic furrow (Carroll and Whyte 1989). Perhaps ectopic rough expression interferes with the expression of hairy and/or other genes active in this region; such genes may be required for morphogenetic furrow movement. It is unlikely that rough plays a critical role in movement of the morphogenetic furrow in wild-type discs, because progression of the furrow occurs in the absence of rough function. Nevertheless, ectopic rough expression is the only treatment known to reversibly arrest the movement of the furrow and should provide an important tool for studying the mechanism of furrow movement.

Although ectopic rough expression clearly alters eye development, it does not change the morphogenetic events that occur in other imaginal discs. Transplantation studies show that the eye imaginal disc cells are partially determined as retinal tissue before the morphogenetic furrow passes through the disc (Hadorn 1968). Lebovitz and Ready (1986) have demonstrated that cells anterior of the furrow are capable of organizing into ommatidia when transplanted elsewhere in the larval body. Similar results have been obtained for other imaginal disc tissues (Nöthiger 1972). The fact that ectopic rough expression is unable to alter the differentiation of cells in other disc types implies that another factor(s) must be present in the eye disc, which makes the retinal precursor cells competent to respond to rough protein.

Ectopic expression of rough with the sevenless promoter has allowed us to examine the effects of longer term expression in particular ommatidial precursor cells. Expression of rough in the cone cells confuses their developmental fate and ultimately prevents these cells from producing the lens structures needed for each ommatidium. Most significantly, rough is capable of transforming the $\mathrm{R} 7$ precursor cell into an $\mathrm{R} 1-6$ photoreceptor. Previous data show that rough function is required in R2 and R5 to normally instruct R3 and R4 to differentiate as photoreceptors (Tomlinson et al. 1988). However, phenotypic analyses of developing rough eye discs demonstrate that rough function is not necessary for R2 and R5, themselves, to adopt a photoreceptor cell fate (Tomlinson et al. 1988). Two extreme possibilities for the role of rough in R2 and R5 are suggested by these observations: First, rough protein might be involved only in the generation of a signal in R2 and R5 necessary for the correct differentiation of R3 and R4, whereas other aspects of R2 and R5 are unaffected by the lack of rough protein. Alternatively, rough may control all aspects of R2 and R5 development that provide these two cells with an identity different from that of the other photoreceptors. The transformation seen in sevro eyes of the R7 cell into an R1-6 cell strongly favors the latter hypothesis. We think it is likely that the transformed R7 cell has adopted the R2/R5 identity; however, we do not currently have cell markers that differentiate R2/R5 from the other outer photoreceptors, and that would be required to test this hypothesis critically. Our data show that rough is unable to direct an undetermined eye disc cell to become a photoreceptor cell; in a sevro fly, the R7 precursor must express functional sevenless protein for this cell to become a photoreceptor. Thus, in the hierarchy of genes necessary for producing functional R2 and R5 photoreceptor cells, rough appears to act downstream of the specification to become a photoreceptor to specify photoreceptor subtype identity. The genes necessary for the R2/R5 identity are likely to be regulated, directly or indirectly, by rough.

\section{Materials and methods}

\section{Antibodies}

An EcoRI-BglII fragment from the rough cDNA proc 4-2 (Tomlinson et al. 1988) was ligated into the EcoRI and BamHI sites of the protein A expression plasmid pRIT2 (Nilsson et al. 1985). Bacterial extracts were prepared, and the fusion protein was purified from the insoluble fraction by affinity chromatography and gel electrophoresis, as described (Nilsson et al. 1985; Montell and Rubin 1988). Swiss Webster mice were immunized with subcutaneous injections containing 5-10 $\mu \mathrm{g}$ of fusion protein per mouse in $50 \%$ Freund's complete adjuvant and then 3 weeks later in $50 \%$ Freund's incomplete adjuvant. Aqueous $10-\mu \mathrm{g}$ boosts of the fusion protein were then performed at 2- to 
4-week intervals. Mice bled 10-12 days after the fourth and fifth boosts yielded excellent rough antisera. The spleens from two mice that had high titers of rough antibodies were used to produce monoclonal antibodies as described previously (Harlow and Lane 1988).

\section{Immunohistochemistry}

Drosophila eye imaginal discs were dissected from third instar larvae reared at $18^{\circ} \mathrm{C}$ and fixed immediately for 30-40 min at room temperature in PEMP [0.1 M PIPES at (pH 7.0), $2.0 \mathrm{~mm}$ EGTA, $1.0 \mathrm{~mm} \mathrm{MgSO}_{4}, 4 \%$ paraformaldehyde]. Discs were washed for at least $15 \mathrm{~min}$ in PBT $(1 \times$ PBS, $0.2 \% \mathrm{BSA}, 0.1 \%$ Triton X-100) on ice while peripodial membranes were dissected. A blocking step was then performed by incubation of the discs for $15-30 \mathrm{~min}$ on ice in PBTS $(1 \times$ PBT, $5-10 \%$ serum). Primary antibody incubations of the anti-rough polyclonal serum and MAbrol were performed in PBTS for 1-2 hr on ice. Eye discs were washed three times for $5 \mathrm{~min}$ in PBTS and then transferred to a goat anti-mouse horseradish peroxidase (HRP)-labeled (New England Biolabs) or Texas Red-labeled (Jackson ImmunoResearch Labs) secondary antibody solution. Three more 5-min PBTS washes were carried out on the discs after a l-hr incubation in the secondary antibody. HRP-labeled eye discs were placed in a $1 \times$ PBS solution containing 0.5 $\mathrm{mg} / \mathrm{ml}$ dimethylaminoazobenzene (DAB), $0.02 \% \mathrm{CoCl}_{2} \cdot 6 \mathrm{H}_{2} \mathrm{O}$, and $0.003 \% \mathrm{H}_{2} \mathrm{O}_{2}$. The HRP staining reaction was followed under a dissecting microscope and stopped after 3-5 min by immersing the discs in a large volume of $1 \times$ PBS. An ethanol dehydration series $(30,50,70,90$, and $2 \times 100 \%)$ was used to dehydrate stained eye discs prior to mounting in DPX (Fluka Chemicals). Fluorescent-labeled discs were incubated in a 1 $\mu \mathrm{g} / \mathrm{ml}$ solution of Hoechst dye 33258 in $1 \times$ PBS to stain all nuclei and then mounted in $80 \%$ glycerol, $2.5 \% n$-propyl gallate. Fluorescence was observed and photographed on a Zeiss Axiophot microscope equipped with the appropriate filters for Texas Red and Hoechst 33258. Discs stained with MAbBP104 were fixed and prepared as described by Tomlinson and Ready (1987a).

Frozen 10- to $12-\mu \mathrm{m}$ serial sections of third instar larvae were cut from larvae embedded in O.C.T. compound (Miles Scientific). Sections were collected on gelatinized slides, dried at $40^{\circ} \mathrm{C}$, and fixed for $30 \mathrm{~min}$ at room temperature in PEMP. After fixation, the sections were washed twice for $5 \mathrm{~min}$ in $1 \times \mathrm{PBS}$, blocked for $30 \mathrm{~min}$ in PBTS, and incubated in MAbrol in PBTS for $30 \mathrm{~min}$ at room temperature. Three 10-min washes in PBT were performed, and the sections were then incubated for 30 min at room temperature in a goat anti-mouse HRP secondary antibody (New England Biolabs). The staining reaction was identical to that described for eye imaginal discs.

MAbDRO4C5 stainings were carried out essentially as described (de Couet and Tanimura 1987). Briefly, heads were dissected in half, fixed in 3\% formaldehyde $/ 0.15 \%$ glutaraldehyde for $1 \mathrm{hr}$, and embedded in L.R. Gold plastic (Polysciences). Onemicron sections were collected on a drop of water on gelatinized slides, which were allowed to dry at room temperature. The slides were then blocked in PBSAP $(1 \times$ PBS, $0.2 \%$ BSA, $0.05 \%$ saponin) for $30 \mathrm{~min}$, after which the slides were incubated for $2 \mathrm{hr}$ in the primary antibody (in PBSAP plus $5 \%$ serum). The primary antibody was detected with a goat antimouse biotin (Jackson ImmunoResearch Labs), fluorescein/ strepavidin (Jackson ImmunoResearch Labs) sandwich. Fluorescence was observed and photographed as described above.

Embryos were stained and visualized as described by Patel et al. $(1989)$.

\section{Histology}

Fixation and sectioning of adult Drosophila eyes was performed as described (Tomlinson and Ready 1987b).

For SEM, whole adult flies were anesthetized with $\mathrm{CO}_{2}$ and then dehydrated through a graded ethanol series $(25,50,75,2 \times$ $100 \%$ | with $24-\mathrm{hr}$ incubations at each step. The flies were then equilibrated with the low-surface-tension solvent Freon 113 (Ted Pella, Inc.) by passing the samples through a graded Freon series $(25,50,75,2 \times 100 \%)$ in neat ethanol with 24 -hr incubations at each step. After the second $100 \%$ Freon 113 treatment, the flies were air-dried, mounted with TV tube coat (Ted Pella, Inc.) onto SEM stubs, and sputter-coated with a 25-nm-thick platinum coat. Samples were viewed and photographed on an International Scientific Instruments DS-130 SEM.

Cobalt sulfide staining of pupal retinas was carried out as described by Cagan and Ready (1989). The retinal discs from 44-hr pupae were dissected and fixed for 5-15 min at room temperature in $2 \%$ glutaraldehyde, $0.1 \mathrm{M} \mathrm{PO}_{4}(\mathrm{pH} 7.2)$. The fixed discs were then soaked in $2-4 \% \mathrm{Co}\left(\mathrm{NO}_{3}\right)_{2} \cdot 6 \mathrm{H}_{2} \mathrm{O}$ for $5 \mathrm{~min}$ at room temperature. After a brief water wash, the discs were transferred into $1-2 \%\left(\mathrm{NH}_{4}\right)_{2} \mathrm{~S}$ until the discs turned black. The discs were then washed quickly in water and mounted in glycerol or Aqua-Poly/Mount (Polysciences).

\section{Transgenic fly lines}

The rough cDNA proc 4-2 (Tomlinson et al. 1988) was subjected to site-directed mutagenesis (Maniatis et al. 1982) by use of the oligonucleotide ATCTCAACTTTGTGACGTTGCATATGGATATCAAGCTT to replace the EcoRI linker of the cDNA with the normal genomic sequence up to and including the predicted methionine start codon. The resulting Bluescript (Stratagene) plasmid derivative contained a HindIII site just $5^{\prime}$ of the methionine codon. Thus, a HindIII/BgIII digestion of this plasmid released the $5^{\prime} 717 \mathrm{bp}$ of the repaired cDNA. This fragment was purified and ligated in a three-way ligation to a 470 bp EcoRI-HindIII fragment of the heat shock promoter (which corresponds to the XbaI-XmnI fragment of Ingolia et al. 1980) and a BgIII-EcoRI fragment containing the $3^{\prime} 1402 \mathrm{bp}$ of the rough genomic rescue fragment (Tomlinson et al. 1988). The resulting Bluescript plasmid, pbshsro, has a heat shock promoter transcriptionally fused to a rough minigene missing the first intron but containing the second intron and $3^{\prime}$-untranslated region, including the poly(A) site of the genomic rough gene (see Fig. 8). A complete NotI, partial XhoI digest of pbshsro produces a fragment containing the hsro fusion gene. This fragment was purified and ligated into NotI-SalI-cut pDM30, a Pelement transformation vector (Mismer and Rubin 1987), yielding the plasmid phsroI. A HindIII/Xhol digestion of pbshsro releases a 2.1 -kb fragment containing the rough minigene. This fragment was end-filled (Maniatis et al. 1982) and ligated to the sevenless proximal promoter $(-967$ to +89 ; Bowtell et al. 1988/ at an end-filled $\mathrm{XbaI}$ site. The resulting plasmid creates a transcriptional fusion between the basal sevenless promoter and the rough minigene. NotI digestion produces a $3.2-\mathrm{kb}$ fragment containing this fusion, which was cloned into the NotI site of a pDM30 P-element vector containing the $+90 \mathrm{bp}$ to $+9.3 \mathrm{~kb}$ sevenless gene enhancer fragment (Bowtell et al. 1989). This plasmid was called psevroI (see Fig. 8). The rough minigene in phsrol and psevrol has a bacterial translation initiation sequence at its $5^{\prime}$ end. This sequence was replaced with the normal rough translational initiation sequence by a second round of site-directed mutagenesis, and the resultant minigene was introduced into the same P-element vectors as described above to generate the plasmids phsroII and psevroII. The nucleotide sequence upstream of the initiation 


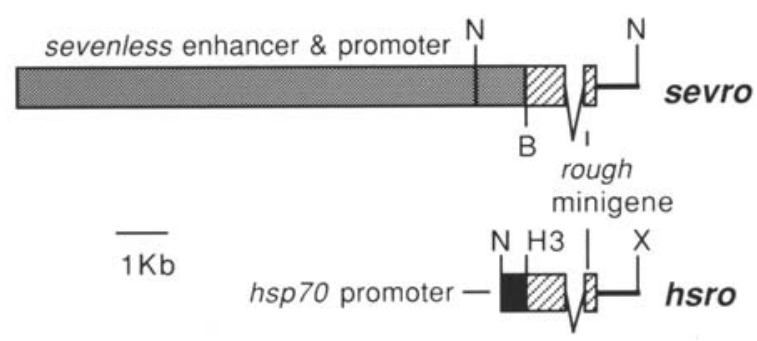

Figure 8. Constructs used to express rough ectopically. The crosshatched boxes represent the exons of the rough gene. The first intron has been removed from the rough minigene, but the second intron and the $3^{\prime}$ portion of the rough genomic rescue fragment (Tomlinson et al. 1988) are still present (lines). A transcriptional fusion between the sevenless promoter (gray boxes) and the rough minigene was created and called sevro. Similarly, the rough minigene was transcriptionally fused to the hsp 70 promoter (black box) yielding hsro. Sites for restriction enzymes are represented as follows: (B) XbaI; (H3) HindIII; (N) NotI; (X) XhoI.

codon in this minigene, beginning at nucleotide -205 in the hsp 70 promoter (Ingolia et al. 1980), was GCGAAAGCTAAGCAAATAGGATCCGTTAACGAA(ATG). Transgenic fly lines containing the hsro and sevro transcriptional fusions were produced by P-element-mediated transformation (Spradling and Rubin 1982). Four independent transformants of hsro I and five transformants of hsro II were obtained. Two sevro I transgenic fly lines were established, both of which had insertions on the second chromosome. Five transpositions of $\mathrm{P}\left[\mathrm{ry}^{+}\right.$, sevro $\left.\mathrm{I}\right] 2$ were generated by crossing $+/ \mathrm{Y}_{;}\left[\mathrm{ry}^{+} ;\right.$sevro $\mathrm{I} \mid 2 / \mathrm{CyO} ; \mathrm{P}\left[\mathrm{ry}^{+} \Delta 2-3 \mid 99 \mathrm{~B}\right.$ (Robertson et al. 1988) ry/TM2Ubx ry males to $\mathrm{XX}_{;}+/+;$ry/ry females. Two transpositions were isolated on $\mathrm{CyO}$, two on TM2Ubx ry, and one on the X. Flies containing four copies of sevro I were generated by crossing $\mathrm{P}\left[\mathrm{ry}^{+}\right.$, sevro $\left.\mathrm{I}\right] 42 \mathrm{~F}$ to a line carrying $\mathrm{P}\left[\mathrm{ry}^{+}\right.$, sevro I $]$on the $\mathrm{X}$ chromosome. Eleven transformant lines of sevro II were isolated. Transformants were made homozygous or introduced into $\mathrm{rO}^{\times 63}$ or $\mathrm{sev}^{d 2}$ genetic backgrounds by standard crosses. No significant difference was observed between constructs that carried the bacterial translation initiation sequence and those that had the rough gene translational start site.

\section{Mosaic analysis}

The sevro insertion on the $\mathrm{X}$ chromosome was used for the mosaic analysis. Males that were $w^{+}$, sevro were crossed to $w^{1118}$ females. Staged female first instar larvae, which were $w^{+}$, sevro/ $w^{1118}$ were $\mathrm{X}$-irradiated with 1000 rads to induce somatic recombination. White eye clones were isolated at a frequency of $1-2 \%$. Along the border of the $w^{-}$(non-sevro) and the $w^{+}$ (sevro) tissues, mosaic ommatidia form that have both sevro and non-sevro photoreceptor cells. Approximately $50 \%$ of the mosaic ommatidia that contained an R7 photoreceptor cell carrying the sevro construct had the transformed $\mathrm{R} 7$ phenotype. Only mosaic ommatidia with the transformed $\mathrm{R} 7$ cell were scored because the incomplete penetrance of the phenotype produced by the sevro construct does not permit meaningful analysis of the other mosaic ommatidia. Only the genotypes of photoreceptor cells were scored.

\section{Acknowledgments}

We thank Laurie Bost and Smadar Admon for helping in the monoclonal antibody production, Mike Simon and David Bow- tell for interesting and productive discussion, Don Pardoe for teaching SEM to B.E.K. and Janice Fischer, Yanfen $\mathrm{Hu}$, and Todd Laverty for assistance with some of the experiments. Numerous contributions were made to this publication by other members of the Rubin lab as well, and we collectively thank those individuals. B.E.K. thanks Andrew Tomlinson for teaching him the eye disc antibody techniques and about eye development. B.E.K. was supported by a National Institutes of Health predoctoral training grant (T32GM0-7232). U.H. was supported by a Jane Coffin Childs Memorial Fund postdoctoral fellowship (61-775).

\section{References}

Baker, N.E. and G.M. Rubin. 1989. Effect on eye development of dominant mutations in the Drosophila homologue of the EGF receptor. Nature 340: 150-153.

Basler, K., P. Siegrist, and E. Hafen. 1989. The spatial and temporal expression pattern of sevenless is exclusively controlled by gene-internal elements. EMBO I. 8: 2381-2386.

Bieber, A.J., P.M. Snow, M. Hortsch, N.H.Patel, J.R. Jacobs, Z.R. Traquina, J. Schilling, and C.S. Goodman. 1989. Drosophila neuroglian: A member of the immunoglobulin superfamily with extensive homology to the vertebrate neural adhesion molecule L1. Cell 59: 447-460.

Bowtell, D.D., M.A. Simon, and G.M. Rubin. 1988. Nucleotide sequence and structure of the sevenless gene of Drosophila melanogaster. Genes Dev. 2: 620-634.

Bowtell, D.D.L., B.E. Kimmel, M.A. Simon, and G.M. Rubin. 1989. Regulation of the complex pattern of sevenless expression in the developing Drosophila eye. Proc. Natl. Acad. Sci. 86: 6245-6249.

Cagan, R.L. and D.F. Ready. 1989. Notch is required for successive cell decisions in the developing Drosophila retina. Genes Dev. 3: 1099-1112.

Campos-Ortega, J.A., G. Jurgens, and A. Hofbauer. 1979. Cell clones and pattern formation: Studies on sevenless, a mutant of Drosophila melanogaster. Wilhelm Roux's Arch. Ent. Org. 186: 27-50.

Carroll, S.B. and J.S. Whyte. 1989. The role of the hairy gene during Drosophila morphogenesis: Stripes in imaginal discs. Genes Dev. 3: 905-916.

de Couet, H.G. and T. Tanimura. 1987. Monoclonal antibodies provide evidence that rhodopsin in the outer rhabdomeres of Drosophila melanogaster is not glycosylated. Eur. I. Cell Biol. 44: 50-56.

Dietrich, W. 1909. Die Facettenaugen der Diptern. Z. Wiss. Zool. 92: 465-539.

Fortini, M. and G.M. Rubin. 1990. Analysis of cis-acting requirements of the Rh3 and Rh4 genes reveals a bipartite organization to rhodopsin promoters in Drosophila melanogaster. Genes Dev. 4: 444-463.

Hadorn, E. 1968. Transdetermination in cells. Sc. Am. 219(5): 110-120.

Harlow, E. and D. Lane. 1988. Antibodies: a laboratory manual. (Cold Spring Harbor Labortory Press, Cold Spring Harbor, New York.

Harris, W.A., W.S. Stark, and J.A. Walker. 1976. Genetic dissection of the photoreceptor system in the compound eye of Drosophila melanogaster. I. Physiol. 256: 415-439.

Hortsch, M., A.J. Bieber, N.H. Patel, and C.S. Goodman. 1990. Differential splicing generates a nervous system-specific form of Drosophila neuroglian. Neuron (in press).

Ingham, P.W. 1988. The molecular genetics of embryonic pattern formation in Drosophila. Nature 335: 25-34.

Ingolia, T.D., E.A. Craig, and B.J. McCarthy. 1980. Sequence of 
three copies of the gene for the major Drosophila heat shock induced protein and their flanking regions. Cell 21: 669679.

Lawrence, P.A. and S.M. Green. 1979. Cell lineage in the developing retina of Drosophila. Dev. Biol. 71: 142-152.

Lebovitz, R.M. and D.F. Ready. 1986. Ommatidial development in Drosophila eye disc fragments. Dev. Biol. 117: 663-671.

Maniatis, T., E.F. Fritsch, and J. Sambrook. 1982. Molecular cloning: A laboratory manual. Cold Spring Harbor Laboratory Press, Cold Spring Harbor, New York.

Mismer, D. and G.M. Rubin. 1987. Analysis of the promoter of the ninaE opsin gene in Drosophila melanogaster. Genetics 116: $565-578$.

Montell, C. and G.M. Rubin. 1988. The Drosophila ninaC locus encodes two photoreceptor cell specific proteins with domains homologous to protein kinases and the myosin heavy chain head. Cell 52: 757-772.

Montell, C., K. Jones, C. Zuker, and G.M. Rubin. 1987. A second opsin gene expressed in the ultraviolet-sensitive R7 photoreceptor cells of Drosophila melanogaster. I. Neurosci. 7(5): 1558-1566.

Nilsson, B., L. Abrahmsen, and M. Uhlen. 1985. Immobilization and purification of enzymes with staphylococcal protein A gene fusion vectors. EMBO I. 4: 1075-1080.

Nöthiger, R. 1972. The larval development of imaginal discs. In The biology of imaginal discs (ed. H. Ursprung and R. Nöthiger), pp. 1-34. Springer-Verlag, New York.

O'Tousa, J.E., W. Baehr, R.L. Martin, J. Hirsh, W.L. Pak, and M.L. Applebury. 1985. The Drosophila ninaE gene encodes an opsin. Cell 40: 839-850.

Patel, N.H., E. Martin-Blanco, K.G. Coleman, S.J. Poole, M.C. Ellis, T.B. Kornberg, and C.S. Goodman. 1989. Expression of engrailed proteins in arthropods, annelids, and chordates. Cell 58: 955-968.

Pollock, J.A. and S. Benzer. 1988. Transcription localization of four opsin genes in the three visual organs of Drosophila; $\mathrm{Rh} 2$ is ocellus specific. Nature 333: $779-782$.

Ready, D.F., T.E. Hanson, and S. Benzer. 1976. Development of the Drosophila retina, a neurocrystalline lattice. Dev. Biol. 53: $217-240$.

Reinke, R. and S.L. Zipursky. 1988. Cell-cell interaction in the Drosophila retina: The bride of sevenless gene is required in photoreceptor cell R8 for R7 cell development. Cell 55: $321-330$.

Robertson, H.M., C.R. Preston, R.W. Phillis, D.M. JohnsonSchlitz, W.K. Benz, and W.R. Engels. 1988. A stable genomic source of $\mathrm{P}$ element transposase in Drosophila melanogaster. Genetics 118: 461-470.

Rushlow, C.A., A. Hogan, S.M. Pinchin, K.M. Howe, M. Lardelli, and D. Ish-Horowicz. 1989. The Drosophila hairy protein acts in both segmentation and bristle patterning and shows homology to N-myc. EMBO I. 8: 3095-3103.

Saint, R., B. Kalionis, T.J. Lockett, and A. Elizur. 1988. Pattern formation in the developing eye of Drosophila melanogaster is regulated by the homeo-box gene, rough. Nature 334: $151-154$.

Spradling, A.C. and G.M. Rubin. 1982. Transposition of cloned P elements into Drosophila germ line chromosomes. Science 218: 341-347.

Tomlinson, A. 1985. The cellular dynamics of pattern formation in the eye of Drosophila. I. Embryol. Exp. Morphol. 89: $313-331$.

- 1988. Cellular interactions in the developing Drosophila eye. Development 104: 183-193.

Tomlinson, A. and D.F. Ready. 1986. sevenless: A cell-specific homeotic mutation of the Drosophila eye. Science
231: 400-402.

- 1987a. Neuronal differentiation in the Drosophila ommatidium. Dev. Biol. 120: 366-376.

. 1987b. Cell fate in the Drosophila ommatidium. Dev. Biol. 123: 264-275.

Tomlinson, A., D.D. Bowtell, E. Hafen, and G.M. Rubin. 1987. Localization of the sevenless protein, a putative receptor for positional information, in the eye imaginal disc of Drosophila. Cell 51: 143-150.

Tomlinson, A., B.E. Kimmel, and G.M. Rubin. 1988. rough, A Drosophila homeobox gene required in photoreceptors R2 and R5 for inductive interactions in the developing eye. Cell 55: $771-784$.

Zuker, C.S., A.F. Cowman, G.M. Rubin. 1985. Isolation and structure of a rhodopsin gene from D. melanogaster. Cell 40: $851-858$.

Zuker, C.S., C. Montell, K. Jones, T. Laverty, and G.M. Rubin. 1987. A rhodopsin gene expressed in photoreceptor cell R7 of the Drosophila eye: Homologies with other signal-transducing molecules. I. Neurosci. 7(5): 1550-1557. 


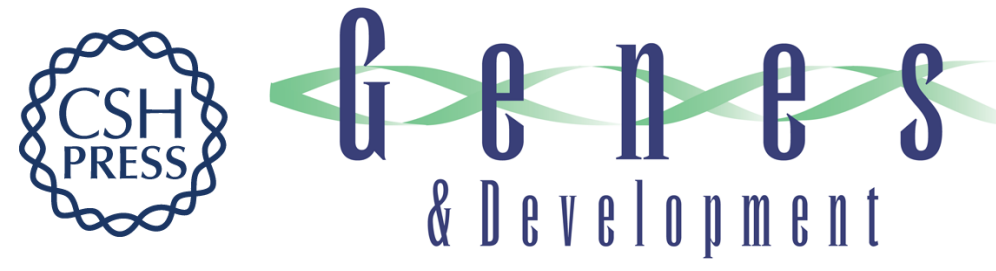

\section{The homeo domain protein rough is expressed in a subset of cells in the developing Drosophila eye where it can specify photoreceptor cell subtype.}

B E Kimmel, U Heberlein and G M Rubin

Genes Dev. 1990, 4:

Access the most recent version at doi:10.1101/gad.4.5.712

References This article cites 39 articles, 11 of which can be accessed free at: http://genesdev.cshlp.org/content/4/5/712.full.html\#ref-list-1

License

Email Alerting Service

Receive free email alerts when new articles cite this article - sign up in the box at the top right corner of the article or click here.

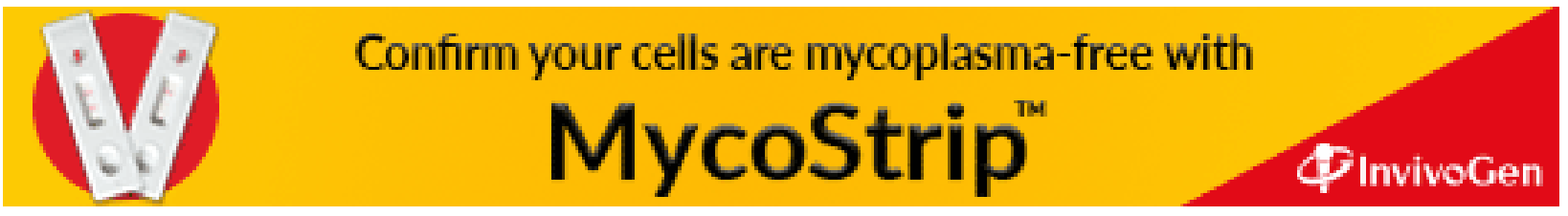

